\title{
Asthma control in adults - unfinished business!
}

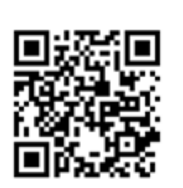

Asthma treatment has advanced tremendously in the last 3 decades. Medical science has provided evidencebased treatment strategies to control over $90 \%$ of persons afflicted with asthma. Evidence of the efficacy of this strategy is manifest by a significant reduction in asthma mortality globally. South Africa (SA), despite being one of the most resourced countries on the African continent, still has an unacceptably high level of mortality. ${ }^{[1]}$ This is also despite the fact that, based on the advocacy of the SA Thoracic Society, every governmentrun primary healthcare clinic has inhaled corticosteroids available on prescription for asthma patients. This begs the question - why does SA have such a relatively high level of asthma mortality?

Possible explanations include:

- Poor management by healthcare providers

- Poor adherence to treatment plans

- Studies conducted in the Western Cape may not represent the status quo in the whole country

- Treatment options available in the public sector may still be suboptimal

- Cofactors such as HIV and tuberculosis may contribute to the mortality and result in misclassification in the death certification.

It is reasonable to accept that all these factors conspire to explain the status of asthma care as reflected in the mortality statistics for SA. It is important to understand asthma care in SA in order to interrogate this high mortality.

The article by van Blydenstein et al. ${ }^{[2]}$ in this issue provides evidence for the poor level of control of asthma in a tertiary hospital setting in Gauteng. The study reported that about $42 \%$ of the adult asthmatics were controlled according to the criteria adopted by the SA Thoracic Society asthma guideline statement. Although the rate of control is relatively high, it appears to be much better than that recorded in a study from the USA. ${ }^{[3]}$ It is especially encouraging if the authors' statement is true that mainly severe asthmatics are referred to and managed in the respiratory clinic. This is not borne out by the relatively high forced expiratory volume in 1 second $\left(\mathrm{FEV}_{1}\right) \%$ and $\mathrm{FEV}_{1}$ / forced vital capacity (FVC) ratio across the three groups.
The high proportion of women with asthma in this cohort is interesting. It is established that women bear a disproportionate burden of asthma deaths and near-fatal asthma. ${ }^{[4]}$ This observation warrants further investigation and is not likely to be simply explained by the better help-seeking behaviour of women.

There are no data on whether the diagnosis of asthma was supported by reversibility criteria and the amount of treatment received. It is important to have additional information about what particular treatments are indeed available in this academic setting respiratory clinic and whether combination inhalers, dry-powder inhalers v. pressurised metred-dose inhalers were available. It is also important for interpretation of the severity of asthma and level of control to get an idea of the quantity of controller medication used or prescribed. In order to better interpret the findings the reader would have also appreciated a description of the staffing of the clinic in respect of pulmonologists, registrars, dedicated asthma-trained nurses and facilities.

Overall, this simple study is laudable as it raises many questions that may form the basis for future research into asthma care in SA. One is actually impressed with the relatively high level of control achieved. But there is still 'unfinished business' when one aims to have the majority of asthmatics well controlled.

1. The Global Asthma Report 2014. http://www.globalasthmareport.org/burden/ burden.php (accessed 15 November 2015).

2. van Blydenstein SA, Nqwata L, Banda NPK, Ashmore P, Wong ML. Factors affecting compliance and control of asthma in patients attending the Respiratory Outpatient Department, Chris Hani Baragwanath Academic Hospital. S Afr Respir J 2015;21(4):91-95. [http://dx.doi.org/10.7196/SARJ.2015.v21i4.43]

3. Gold LS, Yeung K, Smith N, Allen-Ramey FC, Nathan RA, Sullivan SD. Asthma control, cost and race: Results from a national survey. J Asthma 2013;50(7):783-790. [http://dx.doi.org/10.3109/02770903.2013.795589]

4. Chasm RM, Pei YV, Pallin DJ, et al. Sex differences in risk of hospitalization among emergency department patients with acute asthma. Ann Allergy Asthma Immunol 2015:115(1):70-72. [http://dx.doi.org/10.1016/j.anai.2015.03.021]

\section{Umesh G Lalloo}

Director of the Enhancing Care Foundation, Durban University of Technology, Durban, South Africa

S Afr Respir J 2015;21(4):90. DOI:10.7196/SARJ.2015.v21i4.50 